\title{
Assessing consumers' willingness to use tagging technology in tracing halal status
}

\begin{abstract}
This study investigates factors that determine Muslim consumers' willingness to use halal tagging technology. Halal tagging technology refers to the use of mobile phones by consumers to trace whether the halal logo on product packaging is from an authentic source. Five perception factors - complexity, reliability, social influence, facilitating conditions and benefits - were examined as antecedents of willingness to use the halal tagging. Based on data collected from 120 consumers in Malaysia, results indicate that all of the factors except for social influence were significant in affecting the willingness to use the halal tagging technology. Perceived usefulness was found to be the most important factor.
\end{abstract}

Keyword: Halal status; Traceability; Tagging technology; Authenticity; Consumer

behaviour; Willingness to use; Muslim consumers; Mobile phones; Cell phones; Product packaging; Complexity; Reliability; Social influence; Facilitating conditions; Benefits; Halal tagging; Malaysia; Perceived usefulness 